\title{
The Importance of Clinical Psychologist in the Process of Divorce
}

\author{
Jonida MUSTAFARAJ
}

"A. Xhuvani" University of Elbasan, Albania, Faculty of Medical Technical Sciences, Clinical Psychologist, PhD Candidate, European University of Tirana, Albania.

\begin{abstract}
The Family Code in Section 6, 155 is foreseen to include clinical psychologist in the process of divorce in court in cases where the parties are in conflict, when it is claimed elements of physical and psychological violence perpetrated by one or both parties towards each - other or child. The aim of this study was to reveal the importance of the involvement of a clinical psychologist in the process of divorce. So study aims to highlight the necessity of the presence of a clinical psychologist in the process of divorce within the framework of the general principles of the Family Code as long as it guarantees the right to be heard by the parties involved they also guarantee the right presence of a psychologist in the process. The study was conducted on the basis of qualitative methods which deal mostly with history and stories and include subjective meanings, feelings, thoughts and beliefs. The approach used in the study is the epistemological interpretation. Qualitative data were collected on an examination of 60 cases of divorces filed in the District Court of Elbasan in the period January May 2016. This study emphasized the importance and necessity of a clinical psychologist as an expert in the process of divorce as the expertise provided is a guarantee of the process and respect for the rights of the child in the first place and for the parties involved in the process.
\end{abstract}

Keywords: Importance, Clinical Psychologist, Process, Divorce

\section{Introduction}

\section{The role of the clinical psychologist in the process of divorce in court.}

The Family Code in Section 6, 155 is foreseen to include clinical psychologist in the process of divorce in court in cases where the parties are in conflict when the claimed elements of physical and psychological violence are perpetrated by one or both parties towards each - other or child.

The inclusion of a psychologist as an expert in family issues (Bestine, R. 1997) is a revolution in terms of mode of judgement and the treatment of subjects involved in the process of divorce. The expertise offered by this professional is a guarantee of the process and respect for the rights of the child in the first place, and for the parties involved in the process. And through the involvement of expert clinical psychologist, the court has the opportunity to assist the examination of the opinion of the parties and of minors. This happens when the family judges or judges for children in advanced countries have been trained in interviewing and assessing the information received from the child and the two parties.

The presence of clinical psychologists as a professional in the process of divorce is necessary in some important aspects (Bestine, R, and Tuschen, B; 1996):

1. Guarantee to the appropriate parties the state of psycho-emotional in expressing opinion and get valuable information (thinking, feeling, way of feeling) about the issue.

2. Ensuring the institution of the court a specialized professional expertise in the process of assessing claims of the minor and parties and mainly based on two criteria are age and ability of the child to understand.

3. Ensuring the evaluation of the morale and material of the family.

4. Provide mental health assessment 
Applying the principle of involvement in the divorce process is expressed in detail in the specific provisions of the Family Code such as Article 6, 155, 225, 230, 267 etc.

The importance of clinical psychologist in the process of dissolution of marriage (divorce) consists in providing professional expertise to assist the parties and the minor to express their selves and court to realize their opinions, assess climate in the family environment, family dynamics, the presence or not of physical violence or psychological, to assess emotional and social situation of minors and the parties to the court to make a decision as right as possible. (Dehmel at. al, 1974).

So, clinical psychologist involvement in the process of divorce comes as a determination within the framework of the general principles of the Family Code and as long as the parties are guaranteed the right to be heard in the process they are guaranteed and the presence of clinical psychologist.

Being that national legislation does not provide any guidance on whether in case of dissolution of marriage should be the same psychologist who will do the evaluation report psycho-social and at the same time will manage to have a view of the parties and the minors involved in the process. Albanian practice so far has followed the rule of involvement the same psychologist who performs both functions.

\section{Clinical psychologist tasks set by the court in the process of divorce.}

1) What is the family history of the parties already seeing positive and negative sides in order that the parties are released from the crisis on their personal relationships to be seen in the perspective of the child's interest?

2) What are the capabilities of each parent effectively?

3) What are the parental duties for every parent that have performed in the past?

4) What is the relationship of each parent with the child?

5) How parents can cooperate effectively together in well-grown of the children?

6) How is the mentally healthy of the parents?

7) What is the coping ability and personality of the child?

8) What are the moral and material conditions of the parties?

9) Is it possible for parents to provide adequate care for children?

10) What is the clinical psychologist's opinion regarding to the evaluation of statements of minors in accordance with their age and development of their mental and social situation?

11) What is the clinical psychologist's opinion regarding the evaluation of the statements of the parties?

12) The evaluation of the personality of minors within the dynamics of the family situation in which they are located.

13) Are there indicators of domestic violence or child abuse?

The purpose of this assessment from the clinical psychologist is to help the judge to understand family dynamics and take appropriate measures in relation to the best interests of the minors and the parties involved in the divorce process.

Measuring elements to the present assessment are scientific based, who verify its reliability and validity.

In accordance with the evaluation cases are used these instruments:

- Semi-structured interviews.

-Family Evaluation System by Darlington.

- Psycho-legal assessment by G. B Camerini, L. Volpini, Sergio G., G. De Leo (2009)

- Guidelines for the evaluation of child custody in family (Family Psychological -Association APA).

Definition of terms and their operationalization 
Keyword: Clinical psychologist, Family Code, Psychodiagnosis, structural diagnostics,

Clinical psychologist - is the individual who has received academic formation in clinical psychology as a scientific discipline. Clinical psychologist deals with the evaluation and diagnosis of mental and psychological health, family dynamics with the appraisal, family functioning as a healthy system or not, the provision of therapeutic services etc.

Family - is a key part of the Constitution of Albania, Law No. 9062, dated 8. 5. 2003. Family. Pursuant to Articles 53, 54, 81 and 83 paragraph 1 of the Constitution, proposed by the Council of Ministers.

Psychodiagnosis- consists of psychological diagnosis made upon request. The request may be submitted by the individual himself, from family or from a third entity as a legal institution or school facilities (Deusinger, D, 1986).

Analysis Psychological realizes its goal thanks to psychological tests on psychosocial issues, related legal and case evaluation entity, would give his view, in assessing the personal capacity of the mental health of the man, or the injustice of his treatment, has also cases of prisoners, criminals, definitely go to such a test in order to have the punishment, treatment and judgement of mental health grounds deserved.

Structural Diagnosis - is a traditional form of psychodiagnosis which enables psychologist to identificate and interpretate the results obtained from the development of psychological tests, consultations during psychotherapy sessions, avoiding subjective psychological attitudes (Dieterich, 1976).

\section{Methodology}

The study was conducted on the basis of qualitative methods which deal mostly with history and stories and include subjective meanings, feelings, thoughts and beliefs. The approach used in the study is the epistemological interpretation.

\section{The purpose of research:}

The purpose of this study has highlighted the importance of the involvement of a clinical psychologist in the process of divorce.

So study aims to highlighted the necessity of the presence of a clinical psychologist in the process of divorce within the framework of the general principles of the Family Code as long as it guarantees the right to be heard the parties involved they also guarantee the right presence of a psychologist in the process.

\section{Sample}

Qualitative data were collected on an examination of 60 cases of divorces filed in the District Court of Elbasan in the period January - May 2016.

\section{Study measuring instruments}

- Semi-structured interviews.

-Family Evaluation System by Darlington.

- Psycho-legal assessment by G. B Camerini, L. Volpini, Sergio G., G. De Leo (2009)

- Guidelines for the evaluation of child custody in family (Family Psychological -Association APA).

\section{Results}

Qualitative data were collected on an examination of 60 cases of divorces filed in the District Court of Elbasan in the period January - May 2016.

The following results highlight the importance of clinical psychologist in the process of divorce in terms of the necessity of the process needs.

Assessment of climate in the family as a necessity of the evaluation process by clinical psychologist as an expert in the process of divorce. 


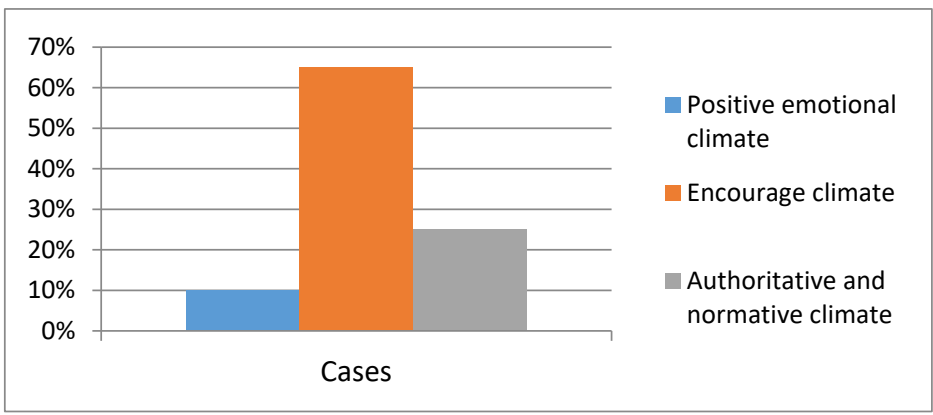

From the above qualitative data obtained from the cases included in the study clearly shows the necessity of the need for environmental assessment of clinical family psychologist as:

In $65 \%$ of cases for divorce prevails a climate of violence and encouraging ongoing conflicts constitute and the basic motivation that drove the parties to this process.

In $25 \%$ of cases for divorce prevails a climate of authoritarian violence and constant conflicts constitute the basic motivation that drove the parties to this process and only $10 \%$ of the cases the climate in the family was quiet, not tense in higher level.

Assessment of psychological health of the parties as a necessity of the evaluation process by clinical psychologist as an expert in the process of divorce.

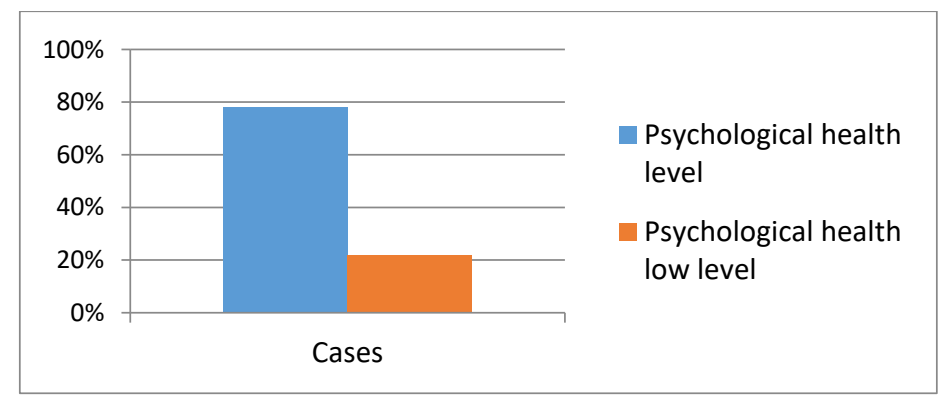

From qualitative data above obtained from the cases included in the study clearly shows the necessity of the need for assessment of psychological health psychologist clinical as $78 \%$ of cases after evaluation by the expert result in psychological health on average and $22 \%$ with low levels psychological health.

Assessment of the authenticity of claims for the exercise of physical or psychological violence by the parties as a necessity of the evaluation process by clinical psychologist as an expert in the process of divorce.

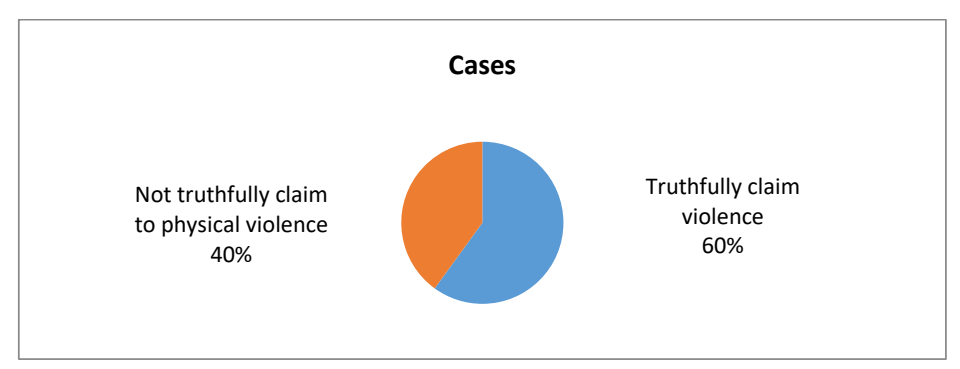


Qualitative data cases included in the study after evaluation by a psychologist clinical expert in the process of dissolution of marriage it shows that in $60 \%$ of cases claim the exercise of physical violence Amongst the parties is true the only $40 \%$ of cases not proven legally its authenticity.

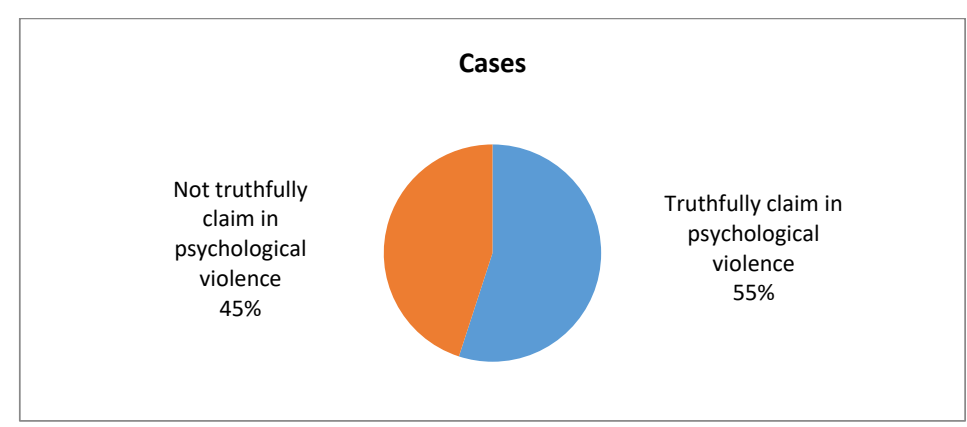

Qualitative data cases included in the study after evaluation by a psychologist clinical expert in the process of dissolution of marriage it shows that in $55 \%$ of cases the claim to exercise psychological violence amongst the parties is real and only in $45 \%$ of cases not proven legally its authenticity.

\section{Conclusions}

This study emphasized the importance and necessity of a clinical psychologist as an expert in the process of divorce as provided expertise is a guarantee of the process and respect for the rights of the child in the first place and the parties involved in the process.

The above results of qualitative stressed the importance of the clinical psychologist in the process of divorce in:

- Assessment of the climate in the family as a necessity of the evaluation process by clinical psychologist as an expert in the process of divorce.

- Assessment of the psychological health of the parties as a necessity of the evaluation process by clinical psychologist as an expert in the process of divorce.

- Assessment of the truthfully of the claims for the exercise of physical or psychological violence by the parties as a necessity of the evaluation process by clinical psychologist as an expert in the process of divorce.

\section{References}

[1] AMATO P. R., BOOTH A. (1996): "A prospective study of parental divorce and parent-child relationships", Journal of Marriage and the Family, 58, 2, 356-365.

[2] Amelang, M and Zielingski, W (2002) ; Psychologische Diagnostik und intervention.

[3] Altavilla E. (1925); La psichologia giudiziaria, UTET, Torino.

[4] Bastine, R. (1997) Klinische Psychologie,Bd. 1, Sttutgart:Kohlhammer

[5] BANDINI T., LAGAZZI M. (2000): Lezioni di psicologia e psichiatria forense, Giuffrè, Milano.

[6] BION W. R. (1961): Esperienze nei gruppi, Armando, Roma, 1971.

[7] Bricklin B. (2005); Nuovi test psichologici per l'affendamento dei figli in casi di separazione e divorzio; Milano.

[8] Cavedon A. (2001) Tecniche di intervista in forza ; pp. 86; 473

[9] CAMERINI G. B., DE LEO G., SERGIO G., VOLPINI L. (2007): "Criteri e strumenti di valutazione delle capacità genitoriali", MinoriGiustizia, 3, 46-57. 
[10] CESARANO F. (1997): "Attività peritale e psicologia clinica", in CIGOLI V., GULOTTA G., SANTI G. (a cura di): Separazione, divorzio e affidamento dei figli, Giuffrè, Milano.

[11] CIGOLI V. (1997): "Teorie e consuetudini come fonte di problemi. Verso una perizia sistemica", in CIGOLI V., GULOTTA G., SANTI G. (a cura di): Separazione, divorzio e affidamento dei figli, Giuffrè, Milano.

[12] Dehmeld et. al (1974) In: Amelang, M and Zielingski, W (2002) ; Psychologische Diagnostik und intervention.

[13] Deusinger, (1986) In: Amelang, M and Zielingski, W (2002) ; Psychologische Diagnostik und intervention.

[14] http://www. psicologiaecomunicazione. it/consulenza-tecnica-di-parte-nei-casi-di-separazione-o-divorzio-deiconiugi_2769527. htm 